\title{
Identification of EGFR kinase domain mutations among lung cancer patients in China: implication for targeted cancer therapy
}

\author{
Bao Ming QIN ${ }^{1}$, Xiao $\mathrm{CHEN}^{1}$, Jing De $\mathrm{ZHU}^{2}$, Duan Qing PEI ${ }^{1, *}$ \\ ${ }^{1}$ Guangzhou Institute of Biomedicine and Health (GIBH), Chinese Academy of Sciences, Guangzhou 510663 China \\ ${ }^{2}$ The State-key Laboratory for Oncogenes and Related Genes, Shanghai Cancer Institute, Shanghai Jiatong University, \\ LN2200/25, Xietu Road, Shanghai 200032, China
}

\begin{abstract}
Lung cancer is one of the leading causes of death with one of the lowest survival rates. However, a subset of lung cancer patients who are of Asian origin and carry somatic mutations in epidermal growth factor receptor or EGFR have responded remarkable well to two tyrosine kinase inhibitors, gefitinib and erlotinib. While EGFR mutation profiles have been reported from Japan, South Korea, and Taiwan, there is no such report from mainland of China where the largest pool of patients reside. In this report, we identified ten somatic mutations from a total of 41 lung cancer patients in China. Among them, seven mutations were found in 17 adenocarcinomas. In contrast to previous reports, eight of these mutations are deletions in exon 19 and two of these deletions are homozygous. These results suggest that a large portion of Chinese adenocarcinoma patients could benefit from gefitinib or erlotinib. This unique mutation profile provides a rationale to develop the next generation of EGFR inhibitors more suitable for the Chinese population.
\end{abstract}

Keywords: lung cancer, epidermal growth factor receptor (EGFR), somatic mutation.

\section{INTRODUCTION}

Among various cancers, lung cancer is the leading cause of death for men and women both in China and around the world. Non-Small Cell Lung Cancer (NSCLC) accounts for about $85 \%$ of lung cancer and its advanced form is refractory to most chemotherapies $[1,2]$. Recently, two drugs, gefitinib (Iressa) and elrotilib (tarceva), that target the EGFR tyrosine kinase (TK) activity were approved by different countries to treat NSCLC $[3,4]$. Initially, the response rate to gefitinib was poor $(\sim 10 \%)$ among patients in the United States, but with very dramatic improvement in those who responded. However, the response rates among Japanese patients were approaching $30 \%$, suggesting a genetic basis for this response. The molecular basis for this apparent gap between two patient groups was elucidated by the discovery of somatic mutations in the EGFR kinase domain in those patients who responded well to gefitinib $[5,6]$. It became apparent that those patients responded well harbored somatic mutations in the kinase domain of EGFR,

\footnotetext{
*Correspondence: Duan Qing PEI
}

E-mail: pei_duanqing@gibh.ac.cn made from exons $18-21$, and close to $30 \%$ of the Japanese patients had mutations $[5,6]$. Biochemically, mutated EGFRs are more sensitive to gefitinib than to wild type EGFR, which explains the improved response in those patients with EGFR mutations [5, 6]. Subsequent studies confirmed these findings and expanded the mutation profiles to patients from Japan, South Korea, Taiwan and other parts of the world [7-9]. These results suggest that the largest patient group who may benefit from EGFR inhibitors should be in Asia. However, the mutation profile among lung cancer patients in mainland of China has not been determined.

We searched for EGFR mutations in Chinese NSCLC patients by sequencing exons 18-21 amplified from genomic DNA samples. We screened 41 cases of NSCLC patients, ten samples of lung tissues of non cancerous patients and seven human cancer cell lines, including two from lung cancer. Somatic mutations were found in lung cancer tissues but not in normal lung tissues, nor in cancer cell lines. Although the types of mutations are similar, the overall mutation profile among Chinese lung cancer patients appears to be quite unique from published data, with eight out of the ten mutations are deletions in exon 19, of which six are heterozygous and two are homozygous 
mutations. These results, although relatively small in sample size, represent the first such report from China where a potentially large patient population resides.

\section{MATERIALS AND METHODS}

\section{Patients and cell lines}

Genomic DNA from 41 NSCLC and 10 non-cancerous lung tissues were obtained from The State-key Laboratory for Oncogenes and Related Genes, Shanghai Cancer Institute, Shanghai Jiaotong University, Shanghai. There were 30 males and 11 females with an age at diagnosis ranging from 43 to 77 (median 57) in male, from 31 to 64 (median 48) in female. Seventeen of these patients were adenocarcinoma, 21 were squamous cell carcinoma and 3 were adenosquamous cell carcinoma. There were 21 non-smokers and 20 smokers. We also investigated seven human cancer cell lines including two lung cancer cell lines 95D, NCI-H460; two prostate cancer cell lines PC-3, Du-145; and others including Hela, HT-1080 and MCF-7.

\section{Isolation of genomic DNA fragments by PCR and iden- tification of mutations by sequencing}

For genome screening, four sets of primers corresponding to exons 18-21 were designed and synthesized; for screening cell lines, primers for amplification of the tyrosine kinase domain on cDNA were also designed and synthesized (Tab. 1). Total RNA was extracted from each cell line by Trizol Reagent from Invitrogen. After genomic DNA digestion with TaKaRa's DNase I (RNase-free), 5 ig total DNA-free RNA was reverse-transcripted by SuperScrip III from Invitrogen. The RT product was diluted corresponding to $50 \mathrm{ng}$ total RNA per $\mu 1.1 \mu 1$ sample was used in the following $40 \mu 1$ PCR amplification of the tyrosine kinase domain. $94^{\circ} \mathrm{C}$ for $5 \mathrm{~min}$ for initial denaturing, 33 cycles at $94^{\circ} \mathrm{C}$ for $30 \mathrm{sec}, 62^{\circ} \mathrm{C}$ for $30 \mathrm{sec}$, and $72^{\circ} \mathrm{C}$ for $30 \mathrm{sec}$ for exons and $1 \mathrm{~min}$ for cDNAs, and final extension was 10 min at $72^{\circ} \mathrm{C}$. The resulting DNA was purified and sequenced on an ABI 377 (Foster city, CA). For genomic sequencing, exons 19-21 were amplified from genomic DNA samples individually. The DNA fragments were purified by agarose gel and sequenced on an ABI 377

Tab. 1 Primers for amplification of EGFR tyrosine kinase domain exons from Chinese NSCLC tissues and EGFR tyrosine kinase domain of cDNA from cancer cell lines

\begin{tabular}{|c|c|c|c|c|}
\hline Primer & Exon & Sequence (5'-3') & $\mathrm{Ta}\left({ }^{\circ} \mathrm{C}\right)$ & Product length (bp) \\
\hline E18F1 & 18 & AATGAGCTGGCAAGTGCCGTGTCCTG & 59.0 & 425 \\
\hline E18R1 & 18 & ССТСТCAATAACTTGGGAAAAACACTG & & \\
\hline E19F1 & 19 & AGCCCCCAGCAATATCAGCCTTAGGTG & 59.6 & 446 \\
\hline E19R1 & 19 & ATGGGAGAGGCCAGTGCTGTCTCTAAG & & \\
\hline E20F1 & 20 & GCATTCATGCGTCTTCACCTGGAAGG & 62.2 & 385 \\
\hline E20R1 & 20 & GCACACACATATCCCCATGGCAAACTC & & \\
\hline $\mathrm{E} 21 \mathrm{~F} 1$ & 21 & CGCCAGCCATAAGTCCTCGACGTGGAG & 61.9 & 386 \\
\hline E21R1 & 21 & TCTGGAGAGCATCCTCCCCTGCATGTG & & \\
\hline EGFRTKF1 & $\mathrm{TK}$ & GGAGAAGCTCCCAACCAAGCTCTCTTG & 60.2 & 981 \\
\hline EGFRTKR1 & $\mathrm{TK}$ & GCCCTGCTGTGGGATGAGGTACTC & & \\
\hline
\end{tabular}

Tab. 2 Somatic mutations in the Tyrosine kinase domain of EGFR in Chinese patients of Non-Small-Cell Lung Cancer

\begin{tabular}{|c|c|c|c|c|c|c|c|c|c|}
\hline No. & Histology & Gender & Age & $\begin{array}{l}\text { Smoking } \\
\text { status }\end{array}$ & Exon & Alteration type & Sequence alteration & Nucleotide & Amino acid \\
\hline 8 & Ad & $\mathrm{F}$ & 42 & Never & 19 & Heterozygous & 2235-2249deletion & GGAATTAAGAGAAGC & Del-1 \\
\hline 10 & $\mathrm{Sq}$ & M & 57 & Never & 19 & Heterozygous & 2235-2249deletion & GGAATTAAGAGAAGC & Del-1 \\
\hline 13 & Ad & M & 59 & Ever & 19 & Heterozygous & 2235-2249deletion & GGAATTAAGAGAAGC & Del-1 \\
\hline 20 & Ad & M & 55 & Ever & 19 & Heterozygous & 2235-2249deletion & GGAATTAAGAGAAGC & Del-1 \\
\hline 24 & $\mathrm{Ad} / \mathrm{Sq}$ & M & 60 & Ever & 19 & Homozygous & 2240-2254deletion & taagagaagcaacat & Del-2 \\
\hline 35 & $\mathrm{Ad} / \mathrm{Sq}$ & M & 43 & Ever & 19 & Heterozygous & 2235-2249deletion & GGAATTAAGAGAAGC & Del-1 \\
\hline 44 & Ad & $\mathrm{F}$ & 55 & Never & 19 & Heterozygous & 2240-2254deletion & taagagaagcaacat & Del-2 \\
\hline 57 & Ad & $\mathrm{F}$ & 44 & Never & 19 & homozygous & $\begin{array}{l}\text { 2240-2254deletion } \\
\text { 2309-2312deletion }\end{array}$ & $\begin{array}{l}\text { taagagaagcaacat } \\
\text { acaa(del) \& }\end{array}$ & Del-2 \\
\hline 41 & Ad & M & 64 & & 20 & Heterozygous & $\& 7 b p$ insertion & ctggtgg(insertion) & Del-3/In \\
\hline 34 & Ad & $\mathrm{F}$ & 50 & Ever & 21 & heterozygous & 2573 substitution & $\mathrm{T}>\mathrm{G}$ & Substitution-1 \\
\hline
\end{tabular}

The clinical information of 10 cases of patients with EGFR TK mutations were shown here. The shaded areas showed 3 cases with nonadenocarcinoma. 
A $\quad \begin{array}{ccc}741 & 751 & 761\end{array}$

EKVKIPVAIKELREATSPKANKEILDEAYV Wild Type EGFR

EKVKIPVAIK--------TSPKANKEILDEAYV Del-1: E746-A750del

EKVKIPVAIKE---------SPKANKEILDEAYV Del-2: L747-T751del

B $\underset{*}{761} \underset{*}{771}$

NKEILDEAYVMASVDN--PHVCRLLGI NKEILDEAYVMASVAGGPHVCRLLGI

C $\quad \underset{*}{851} \quad \stackrel{861}{*}$

KTPQHVKITDFGLAKLLGAEEKEYH Wild Type EGFR KTPQHVKITDFGRAKLLGAEEKEYH Substitution: L858R
Fig. 1 EGFR tyrosin kinase mutations found in Chinese NSCLC patients. The three classes of mutations are in-frame deletions in exon 19 (Del-1 and Del-2 in A), in-frame deletion and insertion in exon20 (Del-3/In in $\mathbf{B})$ and substitution in exon 21 (Substitution in C). The shaded areas represent the altered amino acid.
A
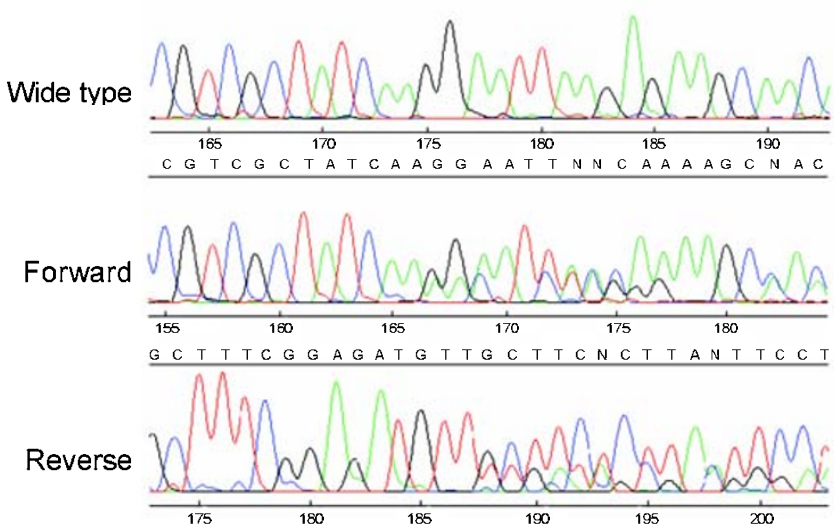

\section{B}

Forward

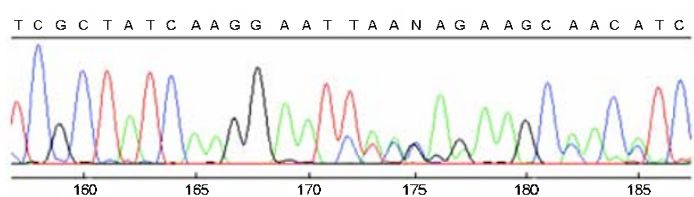

Reverse

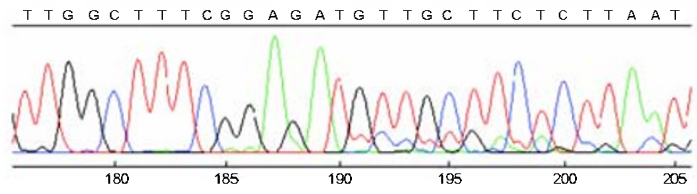

C

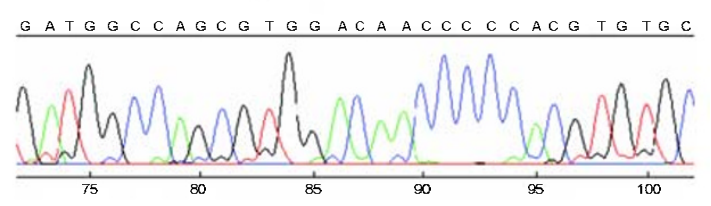
G ATGGCCAGCGTGGATGNCNCCCNCCTGNGN

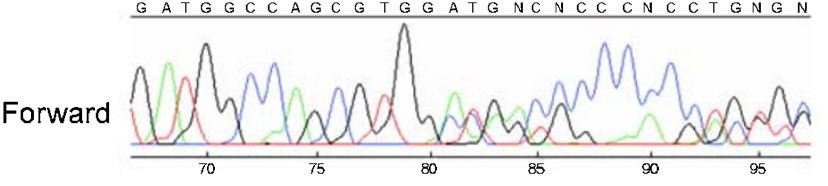

D

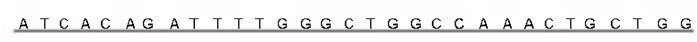

Wide type

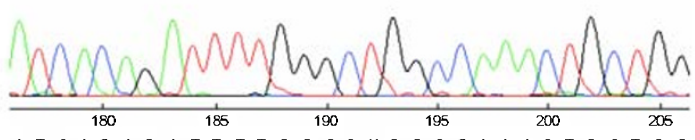

Forward

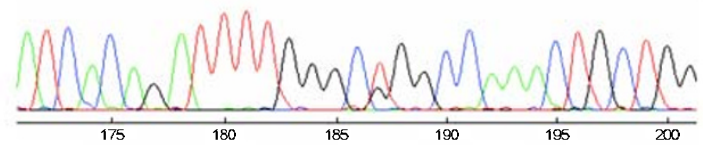
$A C C C A G C A G T T T G G C C N G C C C A A A A T C T G T G$

Reverse

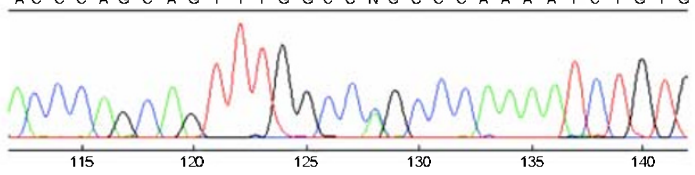

$E$

AGCTATCAAGGAATTCCGAAAGCCAACAAG

Forward

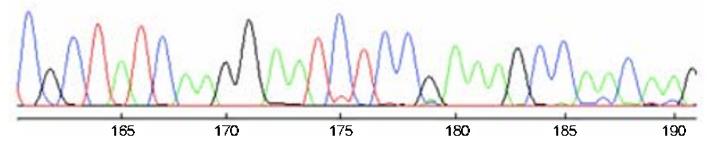

Fig. 2 Four types of EGFR TK mutations found in Chinese NSCLC patients. The matched non-cancerous lung tissues showed no mutation in all the 10 cases. All the cases except No. 24 and 57 were heterozygous mutation. (A): del E746-A750 (No. 8, 10, 13, 20 \& 35); (B): del L747-S752 in S (heterozygous No. 44); (C): DN (770-771) del \& AGG in (No. 41); (D): L858R (No. 34); (E): homozygous No.24 \& 57. 
sequencer. One strand was sequenced first to identify the mutation and then confirmed by sequencing the opposite strand.

\section{RESULT AND DISCUSSION}

\section{Identification of EGFR mutations among lung cancer patients in China}

We identified a total of ten somatic mutations from 41 lung cancer patients (Tab. 2). We also sequenced the matching normal genomic DNAs and found no mutations, thus confirming that the mutations identified are of somatic origin. No mutation was identified in seven cancer cell lines and ten normal lung samples. Among the ten mutations, eight cases were deletions in exon 19, one point-mutation in exon 21 and one deletion/insertion in exon 20 (Fig. 1). When compared to published data, three of these mutations were identified previously [9], i.e. the in-frame deletions of 746-750 or 747-751 amino acids in exon 19, the substitution of L858R in exon 21 (Fig. 1 and 2)]. The deletion/insertion in exon 20 appears to be novel at this point Interestingly, although most (8 out of 10) of the mutations were heterozygous, two (No. 24 and 57) were homozygous (Fig. 2).

\section{Unique mutation profile among Chinese NSCLC pa- tients}

The frequency of mutations reveal a difference between Chinese patients in this study and patients reported recently. There was an unusually high frequency for the deletions in exon 19 (80\% in China versus 46-47\% in Japan, Korea

Tab. 3 Different frequencies of 3 classes of EGFR TK mutations in NSCLC from this and other studies

\begin{tabular}{llccc}
\hline Exon & Mutation & \multicolumn{3}{c}{ Mutation No. (\%) } \\
& & Chinese Japanese [9] & Muti-countries [10] \\
\hline 19 & Deletion & $8(80)$ & $52(47)$ & $62(46)$ \\
20 & $\begin{array}{l}\text { Duplication } \\
\text { /Insertion }\end{array}$ & $1(10)$ & $5(5)$ & $12(9)$ \\
21 & Substitution & $1(10)$ & $54(49)$ & $52(39)$ \\
\hline
\end{tabular}

and other countries or regions), and mutations at L858R was much less common in Chinese than in other people (10\% versus $39-49 \%$ ) (Tab. 3). One obvious explanation is that our sample size is small. However, one of the early reports on EGFR mutations identified four deletions and four point mutations at L858R [6], a ratio confirmed in a sample size of 134 with $46 \%$ having deletions in exon 19 and $45 \%$ having point mutations at L858R[9]. Confirming this pattern in a larger sample size may reflect the differences in EGFR mutations among Asians.

\section{Clinical characteristic of EGFR TK mutations}

The EGFR mutations in this study have no association with age (Tab. 4). However, there is a clear segregation of mutations with adenocarcinomas, $7 / 17$ or $41.2 \%$, vs $1 / 21$ or $4.8 \%$ in squamous cell carcinoma, consistent with find-

Tab. 5 Patient charateristics and EGFR mutation

\begin{tabular}{lcc}
\hline Variables & Number & EGFR mutation (\%) \\
\hline A. in NSCLCs & 41 & $10(24.4)$ \\
Gender & & \\
$\quad$ Male & 30 & $6(20)$ \\
$\quad$ Female & 11 & $4(36.4)$ \\
Smoking history & & \\
$\quad$ Never Smoker & 21 & $6(28.6)$ \\
Ever Smoker & 20 & $4(20)$ \\
Histology & & \\
Adenocarcinoma & 17 & $7(41.2)$ \\
Squamous cell carcinoma & 21 & $1(4.8)$ \\
Adenosquamous cell carcinoma & 3 & 2 \\
\hline B. in adenocarcinoma & 17 & $7(41.2)$ \\
Gender & & \\
Male & 9 & $3(33.3)$ \\
Female & 8 & $4(50)$ \\
Smoking history & & \\
Never Smoker & 10 & $4(40)$ \\
Ever Smoker & 7 & $3(42.9)$ \\
\hline
\end{tabular}

Tab. 4 Age distribution of patients with EGFR TK mutations

\begin{tabular}{lcccccc}
\hline Age group & No. of patients & No. of male & No. of female & No. of Mutation & No. of Male Mutation & No. of Female Mutation \\
\hline $31-40$ & 1 & 0 & 1 & 0 & 0 & 1 \\
$41-50$ & 11 & 5 & 6 & 4 & 4 & 3 \\
$51-60$ & 17 & 16 & 1 & 5 & 1 & 1 \\
$61-70$ & 5 & 3 & 2 & 1 & 0 & 0 \\
$71-80$ & 6 & 6 & 0 & 0 & 6 & 4 \\
total & 30 & 10 & 10 & 10 & & 0 \\
\hline
\end{tabular}

*Average age: in male 57 (1714/30), in female 47.6 (476/10). 
ings reported so far (Tab. 5) [7-9]. Moreover, among the adenocarcinoma patients (17 cases), the greater portion of the mutations were found in females (4 in 8 or $50 \%$, Tab. 5), again consistent with published results [7-9]. In Tab. 6, we compared our results with those published data. It is unlikely that EGFR mutations occurred more frequently in non-smokers of NSCLCs in China. However, since all the female patients in this study were non-smokers and the total number was small, the relationship between smoking status and EGFR mutation needs further investigation.

\section{Implication for drug development}

Given the heightened interest in developing EGFR inhibitors for targeted therapy against lung cancer $[1,4$, 11], the mutation profile we identified in lung cancer patients from China should be significant. With a population of 1.3 billion, China has the largest pool of lung cancer patients in the world, thus, representing a formidable challenge as well as an opportunity for the development of targeted therapy against EGFR. Since these patients were never exposed to EGFR inhibitors, these mutations are naturally occurring, perhaps, accumulating during early stages of carcinogenesis. Thus, a sensitive screening test for EGFR mutations should help identify patients who would respond favorably to EGFR inhibitors. It is also possible that EGFR inhibitors could be developed as a chemopreventative agent for lung cancer, especially among the Chinese population. Therapeutically, Chinese patients carrying the mutations we identified should respond well to gefitinib or erlotinib. Given the high frequency of exon
19 deletion, one may argue that a drug could be designed specifically for the EGFR mutant carrying the exon 19 deletion. One may speculate that such a drug could be more efficacious and have a better response rate among Chinese lung cancer patients.

\section{ACKNOWLEDGEMENT}

This work is supported by the GIBH funds provided by the Chinese Academy of Sciences, the City of Guangzhou and Guangdong Province. The authors wish to thank colleagues at GIBH for encouragements and support.

Received, Mar 8, 2005

Revised, Mar 10, 2005

Accepted, Mar 11, 2005

\section{REFERENCE}

1 Minna JD, Gazdar AF, Sprang SR, Herz J. Cancer. A bull's eye for targeted lung cancer therapy. Science 2004; 304:1458-61.

2 Dowell JE, Minna JD. Chasing mutations in the epidermal growth factor in lung cancer. N Engl J Med 2005; 352:830-2.

3 Tanovic A, Alfaro V. Gefitinib: current status in the treatment of non-small cell lung cancer. Drugs Today (Barc) 2004; 40:80927.

4 Ross JS, Schenkein DP, Pietrusko R, et al. Targeted therapies for cancer 2004. Am J Clin Pathol 2004; 122:598-609.

5 Paez JG, Janne PA, Lee JC, et al. EGFR mutations in lung cancer: correlation with clinical response to gefitinib therapy. Science 2004; 304: 1497-500.

6 Lynch TJ, Bell DW, Sordella R, et al. Activating mutations in the epidermal growth factor receptor underlying responsiveness of non-small-cell lung cancer to gefitinib. N Engl J Med 2004; 350:

Tab. 6 EGFR TK mutations in different countries and regions [10]

\begin{tabular}{|c|c|c|c|c|c|c|c|}
\hline $\begin{array}{l}\text { Country or } \\
\text { ethnicity (No.) }\end{array}$ & $\begin{array}{c}\text { No. mutation } \\
(\%)\end{array}$ & $\begin{array}{l}\text { Sex } \\
\text { (No.) }\end{array}$ & $\begin{array}{c}\text { No. mutation } \\
(\%)\end{array}$ & $\begin{array}{c}\text { Smoking } \\
\text { status (No.) }\end{array}$ & $\begin{array}{c}\text { No. mutation } \\
(\%)\end{array}$ & $\begin{array}{l}\text { Histology } \\
\text { (No.) }\end{array}$ & $\begin{array}{c}\text { No. mutation } \\
(\%)\end{array}$ \\
\hline Mainland of & $10(24.4)$ & Male (30) & $6(20)$ & Never (21) & $6(28.6)$ & Adeno (17) & $7(41.2)$ \\
\hline China (41) & & Female (11) & $4(36.4)$ & Ever (20) & $4(20)$ & Other (24) & $3(12.5)$ \\
\hline Taiwan & $32(34)$ & Male (64) & $14(22)$ & Never (55) & $27(49)$ & Adeno (55) & $31(56)$ \\
\hline (93) & & Female (29) & $18(62)$ & Ever (38) & $5(13)$ & Other (38) & $1(3)$ \\
\hline Japan & $71(27)$ & Male (183) & $30(16)$ & Never (78) & $57(60)$ & Adeno (154) & $67(44)$ \\
\hline (263) & & Female (80) & $41(51)$ & Ever (185) & $24(13)$ & Other (109) & $4(4)$ \\
\hline East Asian & $107(30)$ & Male (251) & $47(19)$ & Never (135) & $76(56)$ & Adeno (214) & $102(48)$ \\
\hline$(361)$ & & Female (110) & $60(55)$ & Ever (226) & $31(14)$ & Other (147) & $5(3)$ \\
\hline Unite States & $11(14)$ & Male (43) & $3(7)$ & Never (26) & $7(27)$ & Adeno (44) & $11(25)$ \\
\hline$(80)$ & & Female (37) & $8(22)$ & Ever (54) & $4(7)$ & Other (36) & $0(0)$ \\
\hline Australia & $6(7)$ & Male (58) & $1(2)$ & Never (7) & $4(57)$ & Adeno (36) & $5(14)$ \\
\hline$(83)$ & & Female (25) & $5(20)$ & Ever (76) & $2(3)$ & Other (47) & $1(2)$ \\
\hline Other & $13(8)$ & Male (97) & $1(1)$ & Never (31) & $8(29)$ & Adeno (75) & $12(16)$ \\
\hline ethnicities (158) & & Female (61) & $12(20)$ & Ever (127) & $4(3)$ & Other (83) & $1(1)$ \\
\hline
\end{tabular}

*Adeno: Adenocarcinoma; Other: non-adenocarcinoma lung cancer. 
2129-39.

7 Huang SF, Liu HP, Li LH, et al. High frequency of epidermal growth factor receptor mutations with complex patterns in nonsmall cell lung cancers related to gefitinib responsiveness in Taiwan. Clin Cancer Res 2004; 10:8195-203.

8 Han SW, Kim TY, Hwang PG, et al. Predictive and Prognostic Impact of Epidermal Growth Factor Receptor Mutation in NonSmall-Cell Lung Cancer Patients Treated With Gefitinib. J Clin Oncol 2005; Feb 14: Epub ahead of print. http://dx.doi.org/10.
1200/JCO.2005.01.388

9 Kosaka T, Yatabe Y, Endoh H, et al. Mutations of the epidermal growth factor receptor gene in lung cancer: biological and clinical implications. Cancer Res 2004; 64:8919-23.

10 Shigematsu H, Lin L, Takahashi T, et al. Clinical and biological features associated with epidermal growth factor receptor gene mutations in lung cancers. J Natl Cancer Inst 2005; 97:339-46.

11 Sellers WR, Meyerson M. EGFR gene mutations: a call for global x global views of cancer. J Natl Cancer Inst 2005; 97:326-8. 